\title{
FISCAL INSTRUMENTS IN SUSTAINABLE HOUSING POLICIES IN THE EU AND THE ACCESSION COUNTRIES
}

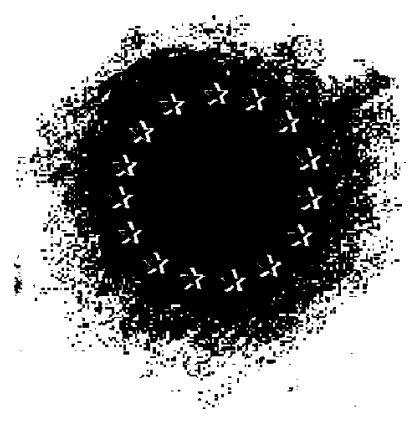

Minna Sunikka*

OTB Research Institute, Delft University of Technology,

The Netherlands

Although progressive government guidelines and knowledge about sustainable housing exist, progress in implementing them in practice has been slow. The perceived costs and the lack of market demand have been identified as the main barriers. A choice of fiscal instruments is essential in sustainable housing policies. This article presents an analysis of economic measures currently used to support sustainable housing in the EU and the accession countries, indicating the areas where policy instruments are either focused or lacking. Based on the country progress reports of the Third European Ministers Conference on Sustainable Housing in Belgium in 2002, the results indicate that environmental taxes and subsidies are used in the EU and the accession countries, but that they have had a low impact on the housing sector. An

\footnotetext{
*Correspondence to: Minna Sunikka, OTB Research Institute for Housing, Urban and Mobility Studies, Delft University of Technology, Thijsseweg 11, 2629 JA Delft, The Netherlands. E-mail: sunikka@otb.indelft.nl (minna sunikka)
}

Copyright @ 2003 John Wiley \& Sons, Ltd and ERP Environment examination of the developments since 1996 shows that apart from energy initiatives resulting from the Kyoto Protocol, the lack of a strong driving force has kept progress slow. Conclusions are based on the analysis findings - the low impact of taxation on housing, the lack of environmental criteria in the reduced VAT rate and the narrow focus of subsidies. This article argues that enlargement of the EU presents opportunities for sustainable housing in Europe, if the fiscal instruments are enforced by legal means. Copyright (c) 2003 John Wiley \& Sons, Ltd and ERP Environment.

\section{INTRODUCTION}

7 he building sector accounts for $25-40 \%$ of the final energy consumption in OECD countries, space heating being the largest proportion of energy consumption in both residential and commercial buildings (Hasegawa, 2002). In the Kyoto commitment, industrialized countries have agreed to reduce their total level of $\mathrm{CO}_{2}$ emissions in 1990 by $5.2 \%$ between the years 2008 and 2012. The 
European Union is preparing to implement the commitment as a community, where its emissions and restrictions are studied as an entity. According to Kyoto Article 4, the division inside the European Union is, e.g. Finland 0\%, the Netherlands $-6 \%$, the UK $-12.5 \%$ and Germany $-21 \%$. The comparison years cited are 1990 and 2010. The Kyoto Protocol has increased pressure on governments to establish strategies aimed at reducing $\mathrm{CO}_{2}$ emissions. In absolute terms, the largest energy end users are households and the tertiary sector (EC, 2001). In the Netherlands, households account for $15 \%$ of the country's total energy consumption (Ministry of Economic Affairs, 1996). Policies to regulate and promote sustainable housing have been developed across Europe, using instruments ranging from mandatory norms to guidelines that can be applied voluntarily.

Despite the available knowledge and instruments, a gap exists between government policy and practice, where sustainable housing has been adapted slowly. Several barriers at the policy and strategy level have been identified, especially the perceived costs of implementing environmental management, the lack of market demand and the poor capture of benefits (Sunikka and Boon, 2002). Consequently, sustainability measures are not adopted in large scale. In Finland, the survey of the National Programme of Sustainable Construction concludes that environmental knowledge is managed by a small group of pioneer organizations and companies that invest in research and development anyway, whereas the majority of the construction sector has not been able to respond to environmental requirements (Ministry of the Environment, 2002). Therefore, the next challenge is to shift sustainable housing from demonstration projects to wider applications. In this process fiscal measures play an important role because extra costs in applying environmental measures are one main barrier to sustainable housing. Incentives are needed to embed environmental measures in normal practice (van Bueren, 1999).
The choice of fiscal instruments is an important issue in sustainable housing policies. This article presents economic instruments that are presently used to encourage sustainable housing in the EU member states and the EU accession countries. Fiscal measures are generally regarded as effective policy instruments, but there can be ideological and practical obstacles in their adaptation. In this article, the instruments are described in relation to environmental effectiveness, economic effectiveness, equity, administrative feasibility and acceptability (OECD, 1991). Opportunities to promote sustainable housing using economic policy measures are discussed. It has to be recognized, however, that the countries studied are in different stages of implementing sustainable housing and, therefore, need slightly different strategies and instruments.

The building stock and the users are of heterogeneous nature, so the effectiveness of policy measures depends on the type of building and the ownership position. Different kinds of building type, e.g. housing or office buildings, have different requirements. This article focuses on housing, because it is the largest sector of the building stock. For example, in Finland housing accounts for 55\% of the total building stock, while households also own $12 \%$ of the total building stock in the form of outbuildings, the remaining 33\% consisting of industrial (15\%), commercial (12\%) and public buildings (8\%) (Vainio et al., 2002). Furthermore, when new housing production in the EU is 1.9 million units per year, or approximately $1 \%$ of the building stock, the real potential for sustainable building and $\mathrm{CO}_{2}$ reduction lies in managing the existing stock of residential buildings (Sunikka, 2001; van der Waals 2001). In the Netherlands, a 3.6 Mton $\mathrm{CO}_{2}$ reduction could be achieved from existing housing if an average investment of $€ 2300$ per dwelling was made and the energy tax was increased 2.5-fold to shorten the pay-back time (ECN, 1998). Another study estimates the $\mathrm{CO}_{2}$ reduction potential to vary between 13 and $44 \%$, which implies a reduction of 3.1-10.6 
Mton, depending on the effectiveness of the measures used, while an average investment of €954 could already ensure a 13\% saving (Slot et al., 1998). The energy saving potential in the EU accession countries equals, and exceeds, that in the EU countries. Effective policies must also reflect different incentives of tenants and owner-occupiers. Many households face significant capital constraints and information barriers. If an investment to improve environmental performance reduces operating costs but has high start-up costs, it may not be taken by tenants who think they will move or if the investment leads to increase in rents (Murakami et al., 2002). The difference between privately owned and rented housing is recognized in this study, but the policy measures are described without making a distinction between their implementation in different ownership sectors. The relation between sustainable housing policies and ownership positions in the EU and the EU accession countries is the subject for another study.

This article is based on the country progress reports of the Third European Ministers Conference on Sustainable Housing in Belgium in 2002 (Novem, 2002a). The meeting aimed to develop the idea of sustainable development in housing policies, to promote the implementation of measures, to improve knowledge exchange between countries and to identify areas of common interest and possible policies at a European level. All EU countries and nine EU accession countries provided national progress reports addressing the existing policy context, policy instruments e.g. legislation and taxation, housing policy priorities, best practices in policy development and future directions. The national reports for the First European Ministers Conference on Sustainable Housing in Copenhagen in 1996, and the Second European Ministers Conference on Sustainable Housing in The Hague in 1997, were used as a reference source for the present study to examine policy developments since 1996 (MVROM, 1996; Seijdel, 1997). Evaluation of the impact of the fiscal measures was not possible in this study, because that kind of data is not yet available in most countries, and it would require modelling and a different research approach.

\section{ENVIRONMENTAL TAXES FOR SUSTAINABLE HOUSING}

The choice of policy instruments is guided by tradition. In economics, environmental problems are considered as externalities. Economic instruments promote the internalization of measurable externalities. There are two principal approaches to the control and correction of external effects: control and correction via taxes and subsidies (Pigou, 1932), and control and correction via the introduction of property rights (Coase, 1960). The Pigouvian tradition, which is dominant in Europe, is based on the idea that externalities exist because of the difference between the private and social marginal cost. With negative externality the social marginal cost exceeds the private marginal cost, suggesting a correction of the private marginal cost in the form of a tax (Boman et al., 1999). Taxation enables the internalization of the external costs of environmental damage and a mechanism for introducing price differentials to encourage more sustainable production and consumption patterns. The OECD countries have accepted the polluter-pays principle (PPP), where they agree to conduct their pollution-control policies so that the property rights lie with the sufferers. According to the polluter-pays principle, the polluters are taxed rather than the sufferers being subsidized. The state, in theory, uses tax revenue to benefit the citizens (Bowers, 1997). However, current prices do not reflect environmental costs and tax systems favour materials over labour (van Bueren, 1999; Dorigoni and Gullí, 2002).

An examination of the national progress reports shows that the Environmental Tax Reform that aims at shifting taxes from labour onto the environment has been implemented 
in most European countries, e.g. in the Netherlands, Belgium, Denmark, Sweden, Finland, the UK, Austria, Germany and Italy (Novem, 2002b). However, the European Environment Agency reports that while pollution and resource tax revenues have grown, they still contribute a very small share and the impact of environmental taxes in practice is still low (EEA, 2002a). For example, despite increases in taxation from 1985 to 2001, energy prices for most fuels dropped and the overall demand for energy increased (EEA, 2002b). The national progress reports show that current environmental tax measures are only indirectly related to housing in terms of energy and $\mathrm{CO}_{2}$ costs, but they do not set targets for the construction sector in particular. A number of EU member states have introduced housingrelated tax measures, e.g. Belgium on water consumption and the UK an aggregate levy on the extraction of virgin construction materials. The Regulatory Energy Tax (REB) was applied in 2001 to Dutch households, which had to pay a third more for their energy. Research shows, however, that only half of the population is aware of the Regulatory Energy Tax and 2\% take it into account in the use of electricity (van der Waals, 2001). Some countries offer tax relief on measures that support sustainable development e.g. a tax relief for property transfers in disadvantaged areas. In the Netherlands, the landfill tax has reduced the amount of waste going to landfill from $49.7 \%$ in 1985 to $4.6 \%$ in 2000 , and increased recycling from $49.5 \%$ in 1985 to $94.3 \%$ in 2000 (Hasegawa, 2002). Since its introduction in 1996, the landfill tax has also contributed to the increase of crushing and recycling sites in the UK (Sunikka, 2001). A landfill tax can effectively reduce the final disposal of construction and demolition waste if the tax rate is set high enough. However, households have no incentive to reduce the volume of waste generated as they receive no financial benefit from it. Financial savings that result from their efforts will be spread across all households, and since the number of households is very large, it is dissipated to the point of insignificance. In an incentive-compatible system households would be charged according to the volume of waste they produce for collection. On the other hand, incentivecompatible charges introduce the risk that households would resort to the illegal dumping of waste (Bowers, 1997). Other regulatory instruments, therefore, such as mandatory reporting and demolition permission, are needed to support these kinds of tax.

Most EU accession countries have introduced taxes that result from environmental damage. In the Baltic countries and Bulgaria, the tax revenue is used for Environmental Investment Funds, according to the recycledtax principle. However, in Poland and Romania, for example, environmental taxes have not yet been introduced and in the Czech Republic taxation law is being drafted. An examination of the country reports shows that in the EU accession countries there are some housing-related environmental taxes. For example, in Bulgaria a discount in the immovable property tax is provided for basic housing with an extra discount for disabled people, whereas the tax is increased for non-built plots in urban development areas (Novem, 2002b).

Governments can use Value Added Tax (VAT) to support environmental investments. Some EU countries, such as the UK, France, Belgium and Luxembourg, apply a reduced VAT rate to renovations in order to encourage maintenance of the existing stock, especially in the social housing sector. In France, VAT of $5.5 \%$ is combined with the PALULOS subsidy for improvements in existing social housing. The combined overall aid package is worth $22 \%$, or $€ 13000$ per housing unit as a ceiling. This has enabled improvements to increase energy efficiency to take place (Sunikka, 2001). In Belgium, the federal government grants a $6 \%$ VAT rate for housing renovations and their adaptation to the needs of the disabled. However, although the criteria for the projects qualifying for the reduced VAT measure favour energy efficiency, the measure is currently used without specific criteria for envi- 
ronmental improvements. It can also be applied to products and materials. In the UK, the reduced VAT is applied to energysaving materials. The EU accession countries do not report that they would use the VAT measure for environmental improvements or renovations.

Many governments are afraid to resort to environmental taxes and other stringent measures in their environmental policy because of the feared political price. Taxation can negatively affect specific sectors of the economy that are relevant to the policymaker or create regional unemployment. This can conflict with the vote maximizing behaviour of the policymaker (Siebert, 1995). In Germany, however, the government has adapted a mandatory approach to sustainable housing. The position of Germany as a forerunner in energy policy is partly enabled by the eco-tax and the act on the sale of electricity from renewable energies that have created incentives for ecological modernization in energy supply (Tritten, 2002). The use of fiscal measures as an essential part of the German environmental policy will have a concrete impact on housing and housing costs in the future. In 1996, the Federal Environment Agency studied energy-induced (heat, hot water, electricity) damage related to habitation. According to their findings, energyrelated costs amounted to $€ 7.7$ billion per year, or roughly €2.6 per square metre of the total housing stock per year. Absolute damage values came to approximately $€ 21$ billion or $€ 7$ per square metre of the total housing stock per year (Lintz, 2000). Thus, the application of the polluter-pays principle would involve passing on all the energy-related costs identified in the study to housing owners and occupants.

Taxes are presumed to achieve the least-cost solution and to provide continuous incentives to search for more cost-effective technologies to improve environmental quality (Siebert, 1995; Hasegawa, 2002). Taxes are effective when they are applied to products consumed in large quantities and combined with clear overall targets. From an economic point of view, they provide a source of financial revenue that can be pointed to environmental programmes. However, taxation can be problematic as a policy instrument. Energy taxes are unpopular with the electorate in general and with industry in particular. A regressive tax on a household's energy use may encourage people to save energy, but it might place an excessive burden on the poorer households, especially in the social housing sector, and create resistance in the privately owned housing sector. Taxation measures are more suitable for the professional construction industry than households, but even then the emission tax can be shifted to the consumer without efforts to change the current practice. Furthermore, the taxation does not define the pollution level: despite the costs to the polluters, the aggregate amount of pollution cannot be predicted. It depends on the forces of supply and demand and will be determined by them. The system of taxes requires supervision and can be bureaucratic, and, due to the time-consuming process of preparing and enacting the taxes, finding the right quality targets and identifying the polluters, prices should apply for a long time period. The allocation conflict can be an implementation barrier: the building owner should make the investment to reduce the operational load of the building, but his motivation is reduced by the fact that the tenant will enjoy the benefits. The use of tax measures depends on the targets: whether the charges are needed for financial purposes or whether more complex mechanisms are necessary to affect the behaviour. Complex systems can be more effective, but costly to apply, whereas simply measures seem practical, but are not necessary effective. It is essential that the target groups accept the taxation measures that are imposed on them. The acceptability can be increased with information, clear targets and schedule of introduction, consultation and progressive implementation. It can be expected that an individual who is better informed about environmental damages has a higher willingness to 
pay (Siebert, 1995). Also due to the acceptance issue, taxation is suitable in countries where sustainable building is already an established issue, e.g. Germany, Denmark and the Netherlands.

\section{INCENTIVES FOR SUSTAINABLE HOUSING}

According to the Pigouvian tradition, if the externality is positive, the corresponding measure is a subsidy (Boman et al., 1999). A subsidy is a transfer of purchasing power from society to the industrialist or individual conditional on it being spent on the investment (Bowers, 1997). A subsidy can also be described as a negative tax.

An examination of the country reports shows that all EU countries have introduced subsidies for sustainable housing in some form, focused on measures to improve energy efficiency (Novem, 2002b). This focus stems from the priorities in national strategies for sustainable housing that, both in the EU and the EU accession countries, are focused on energy-related measures in new housing, whereas issues such as good indoor quality, sustainability of building materials, recycling of building materials and water-saving measures receive less attention. Few progressive countries have established subsidies covering the wider aspects of sustainable housing like the Green Investment in the Netherlands or Eco-Subsidy in Sweden. Austria is one of the countries that relies predominantly on subsidies in its sustainable housing strategy. Of the annual €2 billion subsidies provided for new construction, an important share is targeted at sustainable housing. The promotion scheme for sustainable buildings that has been established by law aims to increase energy efficiency, reduce $\mathrm{CO}_{2}$ emissions and support market penetration of innovative technologies. Consequently, in the Salzburg area for example, $66 \%$ of all new buildings have been submitted to the promotion scheme and energy efficiency in new buildings has increased by approximately $40 \%$ in two years. However, despite the public acceptance, there are still doubts about the efficiency of the promotion schemes regarding favouring new buildings that increase ecological burden and social distribution of the subsidies (Novem, 2002b). An examination of fiscal measures shows that most subsidies in the EU countries are targeted towards new construction despite the considerable environmental and $\mathrm{CO}_{2}$ potential that lies in managing the existing stock. General subsidies to encourage renovation and maintenance of the existing stock exist, but apart from some criteria to favour energy efficiency, renovation subsidies do not support sustainable housing targets in particular. The situation stems from the fact that new construction is given priority in sustainable building policies. A significant proportion of policy instruments for e.g. reducing $\mathrm{CO}_{2}$ emissions target new buildings, while government intervention for upgrading existing buildings has been modest (Hasegawa, 2002). It is easier to apply environmental measures in new construction, both technically and regarding the process, since inhabitants are usually not involved and the target group consists of professional builders.

None of the EU accession countries have established a system of subsidies for sustainable housing in general, but half of them provide incentives and loans to improve energy efficiency in the housing stock (Novem, 2002b). In Slovenia there are subsidies to implement energy efficiency in housing, e.g. in terms of energy-efficient windows and solar collectors for hot water, and profitable loans are available for investments in energy efficiency (Sijanec Zavrl, 2001). In Slovakia government loans at low interest rates are available for investing in sustainable housing projects e.g. insulation and using renewable energy sources. Consequently, 10000 homes have been insulated in five years. Furthermore, the State Housing Funds provide subsidies for renovation, the support package consisting of 
loans at low interest rates, with a condition that residential energy consumption is dropped by at least $20 \%$ as a result of the measures taken (Hadziivanov, 2001). The countries that do not have any subsidies available to support sustainable housing are all EU accession countries where the gross domestic product is low, e.g. Bulgaria, Romania, Poland, Malta and Cyprus. The smaller the GDP, the less likely the country is to have established subsidies. In contrast, the countries that use subsidies as established policy instruments have achieved a stable economic situation. Therefore, the extent to which sustainability is adapted depends on the country's financial situation and the degree to which more urgent housing needs have been met.

The investment in research and development is also greater in wealthy countries that already have knowledge of sustainable housing. The EU accession countries have fewer resources to invest in research. In economically unstable situations risks are avoided and research and development steps are not taken. In the EU countries research and development is one of the main instruments in promoting sustainability and distributing subsidies. The Scandinavian countries, the UK and Germany are investing great sums in providing support for environmental research and development, partly because the construction industry does not have much capacity to undertake research and is slow to adopt new technologies. However, despite information dissemination, the implementation of the research results is often limited to demonstration projects rather than adjusted more widely. Recent market research in the Netherlands and Sweden shows that there is no real market demand for sustainable building that is considered to have a negative impact on shortterm benefits (SBR, 2001; Baumann et al., 2002). When consumers are not interested in investing in environmental measures, subsidies are the main instrument to promote sustainable housing by market actors. In the Netherlands 93\% of the housing associations indicate that subsidies and other fiscal measures encourage them to implement environmental measures (Sunikka and Boon, 2002). Two-thirds of the housing associations find the current system of subsides undeveloped and 54\% consider the subsidies too low (ResCon, 2002).

Subsidy programmes can be useful in the introduction of new technologies below the regulation level. They can encourage innovations and generate knowledge, especially in countries where the concept of sustainable building is new. A recent OECD report on sustainable housing policies concludes that subsidy programmes can encourage energy efficiency investment for both new and existing buildings, if the proportion of free-riders is reduced, but it is unlikely that such programmes could have large-scale impact because they require tax revenue expenditures (Hasegawa, 2002). Subsidies can support social equity better than taxation, especially in the existing housing stock, e.g. an insulation subsidy to reduce energy use can benefit the poor who otherwise could not afford it and reduce their fuel bills (Bowers, 1997). They can also help to overcome the contradiction between investment and benefit in sustainable housing: the owner has to make the start-up investment, whereas the tenant is the one profiting from lower operation costs. Subsidies do not, however, implement the polluter-pays principle adopted by the industrialized countries. They have to be financed by general taxes and in most countries subsidies already account for a large part of the budget. Subsidies should be carefully applied to building products because they can influence pricing in an unhealthy way and prevent environmental improvements when environmental damage costs do not have to be introduced in prices because of subsidies. They can be considered as a barrier to competition, which is in contrast to the principles of the EU. The free-rider problem exists in countries that are experienced in sustainable housing, e.g. in Germany and the Netherlands, where environmental subsidies can benefit parties that would have 
applied the option anyway. Consequently, subsidies for energy saving in buildings were reduced from €122 million in 2002 to $€ 54$ million in the Netherlands in 2002, one main reason being the free-rider problem. In fact, some countries at the forefront of sustainable housing, such as Denmark, do not use subsidies as a main policy instrument but rely on more mandatory measures instead.

Furthermore, an important issue in national environmental policies is to ensure that general subsidies do not support unsustainable development. Subsidies continue to distort the energy market in favour of fossil fuels despite the pressures these place on the environment, while there is much less support for renewable sources or energy conservation (EEA, 2002b). More than 90\% of direct energy subsidies from European governments to the energy industry went to fossil fuels in 1997 (Greenpeace, 1997). In Germany's environmental assessment report in 2001, the OECD recorded that over $35 \%$ of the subsidies in Germany are classified as environmentally harmful. Examples of this can also be seen in the housing sector; there is a need to reform home ownership assistance for housing projects where currently buyers of existing housing receive half of the bonus which is granted for new housing (Tritten, 2002).

\section{POLICY DEVELOPMENTS}

An examination of developments in fiscal policy instruments shows that, despite a number of positive developments, the general situation has changed little since 1996 (MVROM, 1996; Seijdel, 1997). In 1996, most European countries had not yet formulated a policy plan for sustainable housing. In the countries that had policy plans, measures focused on energy saving in new housing and at the building level. Some countries, e.g. the Baltic States, emphasized updating the existing dwellings to the current standards, but in general the attention was focused on new con- struction. The importance of the residential stock in energy saving and the reduction of $\mathrm{CO}_{2}$ emissions have only recently been recognized politically. The contexts in sustainable housing policies are extending towards the existing stock, but this progress is happening very slowly.

Environmental taxation was not yet widely used as a policy instrument in 1996, and the Ecological Tax Reform had just been introduced in Denmark, Sweden and the Netherlands. Taxes on pollution were mentioned in Belgium, Finland, Greece, Italy and the UK. In the housing sector, environmental taxes were introduced e.g. for water consumption in Belgium, for water, $\mathrm{CO}_{2}$ emissions and gas in Denmark and for energy in the Netherlands (MVROM, 1996). In 1996, the reduced VAT rate for renovations had already been introduced in some countries, such as Belgium. However, both taxation measures and the reduced VAT rate were only indirectly related to sustainable housing.

In 1996, most EU countries had established subsidies for sustainable housing, mainly focused on energy savings. France had fiscal allowances to stimulate the use of certain certified products, Germany subsidies for energy and indoor improvements and depreciation on investments in new technology and Austria subsidies for sustainable energy sources and efficient land use. Austria, Belgium and the UK all had subsidies that depended on the income of the applicant. In the EU accession countries there was less scope for subsidies and greater emphasis on regulations instead. Half of the countries had general subsidies to promote the construction of new dwellings and renovation of the existing stock in 1996. In most cases the subsidies favoured sustainability, i.e. energy efficiency, but they did not address sustainable renovation targets.

An examination of the national progress reports in 1996, 1997 and 2002 shows that the Kyoto Protocol has been the main driver in stimulating both the EU and EU accession countries to develop national climate policies 
to achieve the $\mathrm{CO}_{2}$ reduction targets and that this started even before the EU ratified it. Therefore, progress has focused on energy savings and EU directives in the EU countries. Lack of motivating factors, feared costs and low market demand have kept the progress in sustainable housing policies moderate, despite the amount of subsidies that governments have invested in environmental research and development. It has to be considered, however, that the year 1994 is considered as a culmination in policy-making (MVROM, 1996). The developments would be more striking, therefore, if an earlier year were studied.

\section{THE ROLE OF \\ THE EUROPEAN UNION}

The next ministerial conference on sustainable housing will be held in 2004. In the same year, the EU aims to introduce ten new members to the European Union: Poland, Hungary, the Czech Republic, Slovakia, Latvia, Lithuania, Estonia, Slovenia, Cyprus and Malta. The EU strategy for enlargement and accession of the applicant countries will have a considerable impact on European sustainable housing policies. In the national progress reports in 2002, the accession countries present the EU membership and fulfilling its requirements as the main objective of their housing policy (Novem, 2002b).

The environment is one of the areas where the accession countries need to achieve the EU standards. For example, the energy consumption in the EU accession countries is two to three times higher than the EU average. Structures to achieve and to control energy efficiency have to be established in terms of legislation, subsidies and the education of authorities. The modernization of the industrial sector has proven fast progress due to the participation of foreign investors, but the energy rehabilitation of buildings is following at a low pace (Bayer et al., 2002). All the EU accession countries have a large stock of pre- fabricated concrete housing built in the 1960s following the Soviet example. Problems are caused because of the flat roofs, weak joint points in structures, corroded pipes and weaknesses in the engineering systems. In Slovenia, the energy saving potential that could be achieved by renovating the existing block housing is estimated to be $60 \%$, although economically viable energy saving may only reach $29 \%$ if a payback time of less than 10 years is considered feasible (Sijanec Zavrl, 2001). If thermal insulation were improved in prefabricated housing in Latvia, which accounts for a total 20 million square metres, an energy saving potential of $50 \%$ could be achieved. However, the renovation costs to achieve this objective are estimated to be 5.5-6.3 billion USD in Latvia (MVROM, 1996). Sustainable renovation of high-rise residential buildings in Europe and formulation of an upgrade plan for the existing stock will be the main theme for in next ministerial conference on sustainable housing in 2004.

Some researchers consider the EU accession process as an opportunity for low-cost investments with higher emissions savings (Heller, 1998). For example, Poland has managed to reduce its sulphur emissions with $50 \%$ using legislative and fiscal measures (EC, 2002). The EU integrated product policy could also serve as one starting point to tackle unsustainable consumption patterns (EEA, 2002a). Others argue that, given the surplus of carbon-heavy brown coal in these areas, in the accession of new countries to the EU there is the possibility to veto partners of other member states seeking to delay action on e.g. climate change (Grant et al., 2000). While discussing the potential of the environmental policy of the European Union, it has to be considered, however, that the EU is primarily a trade union. The objectives of economic growth and liberalization of trade that drive EU integration are in fact quite unsustainable and can conflict with the development of an environmental policy. For example, the EU energy policy aims to ensure secure supplies of energy at reasonable prices and socially 
to ensure that all EU citizens can afford the energy services they need. Energy prices have generally fallen between 1985 and 2001, offering little incentive for energy saving. Low energy prices are likely to act as a disincentive to energy saving in housing and may encourage energy consumption. Estimated external costs of electricity production amount to 1-2\% of the gross domestic product in the EU, excluding the uncertain costs of global warming. Comparison of these external costs with the current prices for electricity show that the external costs of coal and lignite electricity production are approximately $20-120 \%$ of household energy prices and 7-38\% for gas-fired electricity production (EEA, 2002b). The EU can offer an opportunity for the integrated use of fiscal measures in environmental policy. The EU's Sixth Environment Action Programme stresses the need to internalize the external costs to the environment. It includes the promotion of the use of fiscal measures: environment-related taxes and incentives, a possible use of tradable emissions permits and emissions trading and the undertaking of an inventory and review of subsidies that counteract the sustainable use of energy with a view to gradually phasing them out. However, despite the fact that pollution taxes are increasingly emphasized as an effective instrument of environmental policy, the makers of EU environmental policy lack the ability to levy taxes, tax considerations being subject to a unanimity rule.

\section{CONCLUSIONS}

The country progress reports of the Third European Ministers Conference on Sustainable Housing in Belgium in 2002 were examined to describe which fiscal instruments are presently used in sustainable housing policies in the EU member states and the accession countries. Analysis of the use of taxation and subsidies as policy instruments led to several conclusions about which could be used to encourage sustainable housing across Europe:

Copyright @ 2003 John Wiley \& Sons, Ltd and ERP Environment

\section{Environmental Taxes have a Low Impact on Housing}

Applying the polluter-pays principle that the OECD countries have adopted requires internalizing the external costs of environmental protection. Environmental taxes and the Ecological Tax Reform are increasingly implemented in the EU and in the EU accession countries alike. However, despite positive results from e.g. the introduction of the landfill tax, the impact of environmental taxes remains low in practice, due to their modest rate. Furthermore, the measures are not directly related to housing. Taxation of housing-related environmental damages would be an effective measure to make current practice more sustainable, especially in countries where sustainable housing is already an established issue. It can also increase revenue that can be used for environmental programmes. However, tax measures need to be prepared and applied carefully, preferably progressively, because implementation could create unbearable financial pressure on low-income households.

\section{The Reduced VAT Rate is Not Combined with Environmental Objectives}

The reduced Value Added Tax (VAT) rate for renovations is used to encourage investments in the existing housing stock e.g. in France and Belgium, but without specific environmental criteria. The reduced VAT measure is not currently used in the EU accession countries, but it could be introduced to improve the environmental potential of the existing stock. However, more requirements for sustainable housing and energy saving need to be integrated in the selection criteria for the projects qualifying for the lower VAT rate.

\section{Subsidies are Narrowly Focused}

An examination of the national progress reports shows that all the EU countries have established subsidies to support environmen- 
tal improvements in housing. However, the focus of current subsidies is limited to energy savings and only a few countries have established systems where sustainable housing is considered more widely. Furthermore, most subsidies apply to new housing, widening the gap between new and existing dwellings. There are general fiscal measures to encourage renovation, but their criteria do not set environmental targets. Due to financial restrictions, subsidies are used as a policy instrument in only a few EU accession countries to encourage energy saving, whereas subsidies for sustainable housing in general do not exist. With the right allocation, subsidy programmes can contribute to the adaptation of sustainable housing especially in countries where the concept of sustainable housing is new, whereas the risk of free-riders is increased with experience. However, subsidies have to be financed by general taxes and they are not enough to make sustainable housing common practice if market demand is low. They do not comply with the polluter-pays policy and can be considered as a barrier to competition.

\section{All Fiscal Instruments Need to be Enforced by Legal Means}

None of the fiscal instruments are self-policing. Taxes are not automatically paid and regulations are not necessarily obeyed. Therefore, the use of taxes and subsidies has to be backed up by law, a threat of sanctions and a monitoring programme. It has to be recognized that implementation and enforcement structures entail compliance costs and efforts to governments for implementation, monitoring and revision. A minimum number of well co-ordinated economic instruments on one sector can avoid overlapping, confusion and minimize implementation costs. Furthermore, it is necessary that fiscal measures are compliance with regulations. For example, in the UK, several energy subsidies are available while the thermal regulations remain blurred.

\section{Policy Developments Resulting from the Kyoto Protocol}

An examination of the national progress reports from 1996, 1997 and 2002 shows that developments in fiscal policy instruments since 1996 have been slow. The Kyoto Protocol has increased pressure on governments in the EU and the EU accession countries to establish strategies aimed at reducing $\mathrm{CO}_{2}$ emissions. Consequently, a number of subsidies and taxation measures have resulted from the initiative, but they are still narrowly focused and their impact is low on wider applications. However, the Kyoto Protocol is a positive force and an illustration of the impact that an international initiative can have on national strategies.

\section{The EU Enlargement Presents Opportunities for Sustainable Housing}

The national progress reports show that one main objective of sustainable housing policies in the accession countries is to bring their current practice in line with European standards. The enlargement process of the EU, often presented as negative and risky from a financial point of view, presents great opportunities at an environmental level which are rarely discussed. The enlargement of the EU can support the accession countries in upgrading their existing housing stock, where there is a great capacity to provide environmental benefits. Public funds may not be sufficient regarding the renovation need so financing must be sought for from private-public partnerships and international institutions. To help the accession countries prepare for their membership, the EU has committed itself to financial assistance of more than $€ 3$ billion per year, disseminated through the pre-accession instruments - Phare, ISPA and Sapard - that are focused on the environment and infrastructure (EC-DG Enlargement, 2002). The pre-accession instruments could be orientated to improve the environmental potential of the existing housing. 


\section{Lack of Market Demand is a Continuous Challenge to Sustainable Housing}

Governments across Europe face the challenge of stimulating the market demand for sustainable housing and making consumption habits more sustainable. Sustainable housing is not possible without the involvement of the industry, but the market's ability to solve environmental problems is limited and requires government intervention. Pollution control is a conscious social and political process that should not and cannot be left to market forces (Bowers, 1997). Governments must support sustainable technology and investments in production must be made more attractive by creating a market e.g. using mandatory measures (Wijffels, 2002). In addition to taxes, subsidies and building regulations, the market demand for sustainable housing should be stimulated with the development of other measures, e.g. labelling and standards such as ISO 14001. If the main responsibility in the sustainable housing process is pointed to the government, the question arises whether environmental problems exceed the capacity of the political systems to solve long-term problems. Oystein Dahle, the chairman of the Worldwatch Institute, argues that environmental problems are symptoms of political problems and that government policies are a reaction to, not an anticipation of, a problem (Dahle, 2002). Dahle considers policy development with new and existing instruments as the main challenge to sustainable development.

In the end, the use of fiscal policy instruments depends on the objective. Neo-classical economists define two notions of sustainability in terms of natural capital: weak sustainability and strong sustainability. Weak sustainability is met if all the environmental impacts of private decisions are internalized through Pigouvian taxes and public investment satisfies a cost-benefit test when environmental effects are given a monetary value. Strong sustainability requires that any losses of natural capital in public investment projects are com- pensated for by shadow projects that create natural capital of equal value, so that the stock of natural capital is kept constant or allowed to increase (Bowers, 1997).

\section{REFERENCES}

Baumann H, Brunklaus B, Gluch P, Kadefors A, Stenberg A-C, Thuvander L, Widman J. 2002. Environmental drivers, management and results in Swedish building industry. In Proceedings of the Sustainable Building 2002 Conference, Oslo.

Bayer G, Wennstöm N, Kisliakova A. 2002. Environmental Policies, Strategies and Programmes of the EU Accession Countries in Central and Eastern Europe. ÖGUTWKÖ-OeKB: Vienna.

Boman M, Brännlund R, Kriström B (eds). 1999. Topics in Environmental Economics. Kluwer: Dordrecht.

Bowers J. 1997. Sustainability and Environmental Economics. Longman: Essex.

Coase RH. 1960. The problem of social costs. Journal of Law and Economics 3: 1-44.

Dahle O. 2002. The Challenge. Presentation in the Sustainable Building 2002 Conference, Oslo.

Dorigoni S, Gullí F. 2002. Energy tax harmonisation in the European Union: a proposal based on the internationalization of environmental external costs. European Environment 12: 17-34.

Energieonderzoek Centrum Nederland (ECN). 1998. Nationale Energie Verkenningen 1995-2020, Trends en thema's. ECN: Pettern.

European Commission (EC). 2001. Towards a European Strategy for the Security of Energy Supply, Green Paper. European Commission: Brussels.

European Commission (EC). 2002. Choices for a Greener Future: the European Union and the Environment. Office for Official Publications for the European Communities: Luxembourg.

European Environmental Agency. 2002a. Environmental Signals 2002. http://org.eea.eu.int. [1 September 2002].

European Environmental Agency (EEA). 2002b. Energy and Environment in the European Union. http://org.eea.eu.int. [1 September 2002].

Grant W, Matthews D, Newell P. 2000. The Effectiveness of European Union Environmental Policy. Macmillan: London.

Greenpeace. 1997. Greenpeace Exposes European Energy Subsidy Scandal. 20 May.

Hadziinanov A. 2001. Slovakia, development trends and sustainability promotion. Sustainable Building 3/2001.

Hasegawa T. 2002. Policies for Environmentally Sustainable Buildings, OECD Report ENV/EPOC/WPNEP (2002)5. OECD: Paris. 
Heller T. 1998. The path to EU climate change policy. In Global Competition and EU Environmental Policy, Golub J (ed.). Routledge: London.

Lintz G. 2000. Environmental costs of the construction and the use of residential buildings in Germany. In Proceedings of the Sustainable Building 2000 Conference, Maastricht.

Ministry of Economic Affairs. 1996. Energiebesparingsnota. Ministry of Economic Affairs: The Hague.

Ministry of the Environment. 2002. Ekologisesti Kestävän Rakentamisen Ohjelma, Seurantaraportti. Ministry of the Environment: Helsinki.

Murakami S, Izumi H, Yashiro T, Ando S, Hasegawa T. 2002. Sustainable Building and Policy Design. Institute of International Harmonisation for Building and Housing: Tokyo.

MVROM. 1996. Basic Documentation for the First European Ministerial Conference on Sustainable Housing Policies in Copenhagen 22-23 April 1996. MVROM: The Hague.

Novem. 2002a. Operating Space for European Sustainable Building Policies, Report of the Pan European Conference of the Ministers of Housing Addressing Sustainable Building, Genvalle, Belgium, 27-28 June 2002. Novem: Utrecht.

Novem. 2002b. Country Reports for the European Conference of the Ministers of Housing Addressing Sustainable Building 2002. Novem: Utrecht. http://mrw.wallonie.be/ dgatlp/logement/logement_euro/Pages/Reunions/ Genval/Colloque.htm

OECD. 1991. Environmental Policy: How to Apply Economic Instruments. OECD: Paris.

Pigou AC. 1932. The Economics of Welfare. Macmillan: London.

ResCon. 2002. Markverkenning Woningcorporaties. Novem: Utrecht.
SBR. 2001. Attitude t.a.v. Duurzaam Bouwen en Nationaal Pakket Woningbouw-Utiliteitsbouw. SBR: Rotterdam.

Seijdel R (ed.). 1997. National Progress Reports for the Second European Ministers Conference on Sustainable Housing Policies in Amsterdam September 1997. PRC Bouwcentrum: Bodegraven.

Siebert H. 1995. Economics of the Environment, Theory and Policy. Springer: Berlin.

Sijanec Zavrl M. 2001. Slovenia, government activities at all levels. Sustainable Building 3.

Slot BJM, Poel A, Scholte WK. 1998. KWR 94-96 Analyse Energie en Water. Damen: Rotterdam.

Sunikka M. 2001. Policies and Regulations for Sustainable Building, a Comparative Analysis of Five European Countries. Delft University Press: Delft.

Sunikka M, Boon C. 2002. Environmental policies and efforts in social housing: the Netherlands. Building Research and Information 30(6).

Tritten J. 2002. Environmental Fiscal Reform - Review and Perspectives. International OECD/BMV Conference on Environmental Fiscal Reform: Berlin.

Vainio T, Jaakkonen L, Nippala E, Lehtinen E, Isaksson K. 2002. Korjausrakentaminen 2000-2010, VTT Research Notes 2154, Espoo.

van Bueren E. 1999. Sustainable building policies: exploring the implementation gap. In Sharing Knowledge on Sustainable Building, Maiellaro N (ed.). Kluwer Academic Publishers: Dordrecht; 29-42.

van der Waals J. 2001. $\mathrm{CO}_{2}$-Reduction in Housing, Experiences in Building and Urban Renewal Projects in the Netherlands. Rozenberg: Utrecht.

Wijffels H. 2002. In innovation for sustainability, technology meets the market. In Proceedings of the Economy Ecology Technology Conference, Amsterdam. 